\title{
Effect of Unsaturated Soil Properties on the Intensity- Duration Threshold for Rainfall Triggered Landslides
}

\author{
Melih Birhan KENANOĞLU ${ }^{1}$ \\ Mohammad AHMADI-ADLI ${ }^{2}$ \\ Nabi Kartal TOKER ${ }^{3}$ \\ Nejan HUVAJ ${ }^{4}$
}

\begin{abstract}
Rainfall triggered landslides are one of the most common natural hazards in many countries throughout the world, as well as in Turkey. This study investigates the effect of unsaturated soil properties on landslide-triggering rainfall intensity-duration threshold. In addition to the time to failure, the suction (negative pore water pressure) distribution in the slope, the shape and depth of the failure surface are also evaluated. Properties of soil-water characteristic curve which affect the distribution of suction in the soil in response to changes in water content are varied in a parametric study. Effects of air entry value (relates to particle size), desaturation rate (relates to uniformity of particle size distribution), saturated volumetric water content (relates to void ratio) and residual volumetric water content (relates to fines content and characteristics) are evaluated by determining the intensity-duration threshold numerically by carrying out infiltration and slope stability calculations, using finite element and limit equilibrium methods, respectively. The variation of unsaturated soil properties is found to significantly alter the landslide mechanism/the cause of failure (ranging from mere surface erosion to groundwater level rise in response to complete infiltration), and consequent intensity-duration thresholds for the same slope geometry. Among the parameters considered, air entry value appears to be the most influential parameter. The effects of the slope angle and initial moisture condition on threshold rainfall intensity-duration are also investigated. This study could be useful for creating the basis and mechanical understanding for future research on early warning systems for rainfall triggered landslides.
\end{abstract}

Note:

- This paper has been received on April 12, 2018 and accepted for publication by the Editorial Board on October 09, 2018.

- Discussions on this paper will be accepted by May 31, 2019.

- https://dx.doi.org/10.18400/tekderg.414884

1 Middle East Technical University, Civil Engineering Department, Ankara, Turkey melih.kenanoglu@metu.edu.tr - https://orcid.org/0000-0001-7453-2286

2 Islamic Azad University, Tehran, Iran - ahmadiadli@gmail.com https://orcid.org/0000-0003-3240-7756

3 Middle East Technical University, Civil Engineering Department, Ankara, Turkey - toker@metu.edu.tr https://orcid.org/0000-0001-8858-0510

4 Middle East Technical University, Civil Engineering Department, Ankara, Turkey - nejan@metu.edu.tr https://orcid.org/0000-0002-0909-1135 
Keywords: Unsaturated soil, rainfall triggered landslide, intensity-duration threshold, soil water characteristic curve, suction.

\section{INTRODUCTION}

Slope instability in unsaturated soils is very common in many parts of the world. The rainfall is the major triggering factor, however, the slope topography, geology, hydrology and material characteristics all contribute to development of such instability. In fact, extreme and/or prolonged rainfall events frequently cause landslides in many parts of the world [112]. A rainfall triggered landslide develops due to wetting of an unsaturated soil, by which moisture content increases and suction in the ground decreases. Accordingly, weight of the soil increases while its shear strength decreases and deformations in the soil develop. Modelling of rainfall infiltration and slope instability is quite complex for unsaturated soils, since it is controlled by many variables such as the characteristics of the rainfall and the nonlinear hydraulic and constitutive properties of the soil.

One of the mitigation methods for rainfall triggered landslides is early warning. By using landslide early warning systems, alarms can be set up to warn and evacuate people, and to close the roads and railways near the slopes. In the literature, available methods to predict rainfall-triggered landslides are based on two approaches. The first approach is using physically-based models considering infinite slope mechanism [5-10]. Such physically-based models require an understanding of the physical mechanism which controls seepage and slope stability. Slope stability is evaluated by means of static limit equilibrium for a potential failure surface using infinite slope stability analysis assuming a planar slip surface parallel to the ground surface. Pore pressures are assumed or obtained by simple rainfall infiltration models. These methods generally oversimplify unsaturated soil behaviour.

The second approach relies on empirical studies to define (global, regional or national) rainfall intensity (I) and duration (D) threshold. This threshold is defined as the threshold, or the limit value, of the pair of rainfall intensity and rainfall duration, at or above which the total amount of water infiltrating into the unsaturated soil slope would trigger landslides. This threshold is first introduced by [11] as an intensity versus duration (I-D) plot and it is commonly obtained by statistically evaluating the records of past rainfall events that triggered landslides 11-16] (Fig. 1). Only for the sake of examples and visualizing the shape of the rainfall intensity-duration thresholds, in Figure 1, thresholds for different parts of the world proposed by different researchers are presented. In Figure 1, it can be seen that both high intensity-short duration rainfalls and low intensity-long duration rainfalls can trigger landslides (high intensity can be considered as rainfall intensities greater than $50 \mathrm{~mm} / \mathrm{hr}$ in Figure 1). However, a rainfall with very small intensity might not cause failure even if it rains for a prolonged duration. Statistically-developed empirical thresholds (such as the ones in Figure 1) may be limited by some of the shortcomings of the raw data. For example, archived records of rainfall and slope instability may not be available, the data may not be complete, it may not be precise, or it may have a bias. In some countries such data may not be available, or can be very limited to be able to carry out a statistical evaluation. The data may have a bias such that the rainfalls that caused slope instability may have been recorded more frequently but the rainfalls which did not cause any landslides may not have been recorded. Landslide events which cause damages in urban areas are often recorded but landslides in 
unpopulated areas (for example, in different geological formations and slope angles) are typically not recorded. Moreover different landslide types (for example rockfalls, shallow landslides in unsaturated soils, mudflows, debris flows, deep landslides etc.) are typically not treated separately in the database, while different mechanisms control each of these landslide types [17].

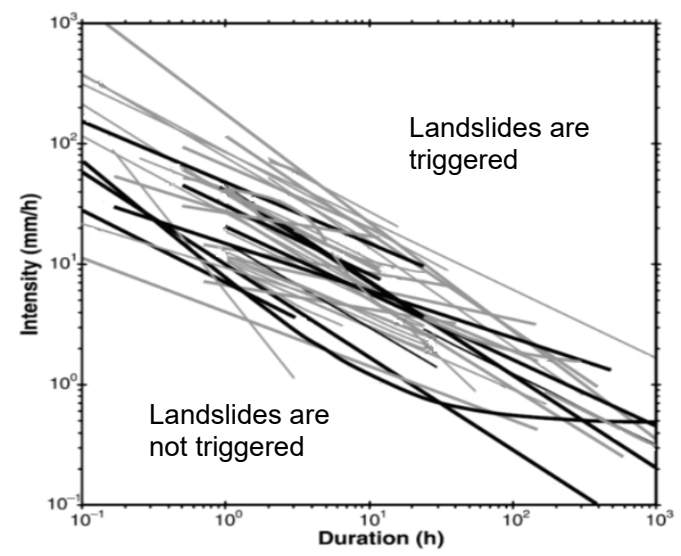

Figure 1 - Rainfall intensity-duration thresholds that are proposed by different researchers for different parts of the world, modified after [15]).

Obtaining a rainfall threshold that triggers a landslide on a particular slope is possible by performing a number of numerical analyses with different rainfall intensity-duration combinations (applying constant rainfall intensity in each analyses until failure) and calculating the factor of safety (F.S.) of the slope. Then a boundary (a threshold) can be generated between "landslide" (F.S. equal to or less than 1.00) and "no landslide" (F.S. equal greater than 1.00) cases. This study investigates the effect of unsaturated soil properties (such as the properties of soil water characteristic curve, SWCC, and the hydraulic conductivity function, HCF) on the distribution of suction in the slope, the shape of the failure surface, failure time, and rainfall intensity-duration threshold. In order to study the effects of changes in characteristics of SWCC, hypothetical soils are needed so that each parameter can be controlled and its effect on the results can be identified individually. SWCC of these soils are generated by changing one of the characteristic parameters (AEV, $\theta_{\mathrm{s}}, \mathrm{DSR}, \theta_{\mathrm{r}}$ ) while keeping others constant. We considered SWCC of a sand (Edosaki sand from $[4,18]$ as starting point and we generated SWCCs with different air entry values (AEV - the suction corresponding to the border of saturated and unsaturated states of the soil); saturated volumetric water contents $\left(\theta_{s}\right)$; desaturation rates (DSR - defined as the rate of change of volumetric water content $(\theta)$ with matric suction $(\Psi))$ and residual volumetric water contents $\left(\theta_{r}\right)$ as defined in Fig. 2 [19].

These hypothetical soils' properties are then used in a 2D numerical model that has been defined in Geo-Slope 2007 software package (SEEP/W and SLOPE/W) [20] for simulation of seepage and slope stability in $7 \mathrm{~m}$ tall finite slopes. Suction distribution in the slope, the 
shape of the slip surface, time to failure and slope instability-triggering rainfall intensityduration threshold were investigated by performing staged seepage (equalization and rainfalling) and limit equilibrium slope stability calculations. Although this general topic has been studied in the literature, the novelties in this study are (i) modeling seepage and slope stability numerically without the assumption of infinite slope, (ii) considering the equalization and rainfall stages using the drying and wetting unsaturated properties of the soils separately (i.e. considering hysteresis in SWCC); (iii) characterizing SWCC through independent physical soil properties, rather than curve fitting parameters, (iv) demonstrating the effects of unsaturated soil properties on the I-D threshold.

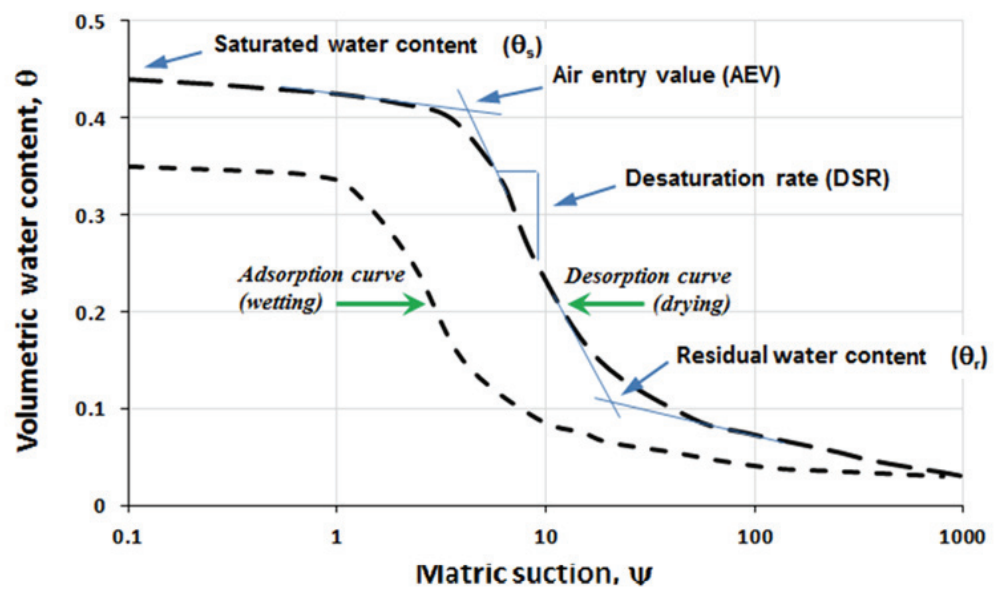

Figure 2 - Drying and wetting soil-water characteristic curve and their key parameters [19].

\section{PARAMETRIC STUDY}

In this study SWCC is defined in terms of four parameters: AEV (air entry value), $\theta_{\mathrm{s}}$ (saturated volumetric water content), DSR (desaturation rate) and $\theta_{\mathrm{r}}$ (residual volumetric water content) (Fig. 2). Each of these parameters has a physical meaning. AEV represents the gradation of the soil, e.g. a soil with a higher AEV is a finer grained soil. Saturated volumetric water content, $\theta_{\mathrm{s}}$, represents the density (a soil with a higher $\theta_{\mathrm{s}}$ value is a denser soil). DSR is related to the uniformity of the material, e.g. the higher the DSR the more uniform grain size distribution curve is. Residual volumetric water content, $\theta_{\mathrm{r}}$, is related to the fines content such that, as the fines content of a soil increases, $\theta_{\mathrm{r}}$ increases. The parameters are different from the curve fitting parameters of the equations that describe SWCC in the literature (such as the parameters $a, m$ and $n$ of [21]). In the following sections the effect of changes in any of these parameters on suction distribution, failure surface, time to failure and I-D plots have been investigated. 


\subsection{Generation of Hypothetical Soils}

Although some measured SWCC curves of real soils are available in the literature, with corresponding grain size distribution curves, they were not sufficient for the purposes of this study. Because, for example, in order to study the effects of fines content, we would like to have SWCC curves of soil with different fines content (as the fines content increases, residual volumetric water content $\theta_{\mathrm{r}}$ increases, and SWCC curve changes), however these were not available in the literature in a systematic way. Therefore, in order to study the effects of changes in SWCC characteristics in a controlled manner, generation of hypothetical soils was necessary.

Estimation of SWCC curve from particle size is possible [e.g. 22, 23, 24]. However the existing methods are computationally cumbersome for a full grain size distribution curve covering many different particle sizes. Obtaining SWCC curves by scaling, e.g. by multiplying the suction values with the same number that is used to multiply the grain sizes, is a reasonable and practical approach used in this study [22-25].

As a starting point, a sand from the literature (Edosaki sand from Japan) whose grain size distribution, wetting and drying SWCC's were measured [4, 18] is used. Edosaki sand is classified as silty sand (SM) according to Unified Soil Classification System. The specific gravity of solids and maximum and minimum void ratios of the soil were reported as 2.75 , 1.59 , and 1.01, respectively, by [4, 18]. Figure 3(a) includes drying and wetting soil water characteristic data for Edosaki sand which has been obtained using Tempe Pressure Cell method for a sample of the same dry density as that in the flume, $1.22 \mathrm{~g} / \mathrm{cm}^{3}[4,18]$ Appropriate curves have been fitted to these data using the equation proposed by [22]. In addition, drying hydraulic conductivity of this soil has been measured as a function of suction by using a permeameter by $[4,18]$. Wetting hydraulic conductivity for Edosaki sand was not measured. Therefore, we deduced it from measured drying hydraulic conductivity data points through drying and wetting SWCCs, assuming there is a negligible hysteresis in HCF when plotted against volumetric water content [26, 27]. In Figure 3(b) HCF data for Edosaki sand are plotted with respect to volumetric water content. These data are compared to some HCF predictions. The method proposed [21], which was found to predict hydraulic conductivity function for this material successfully.
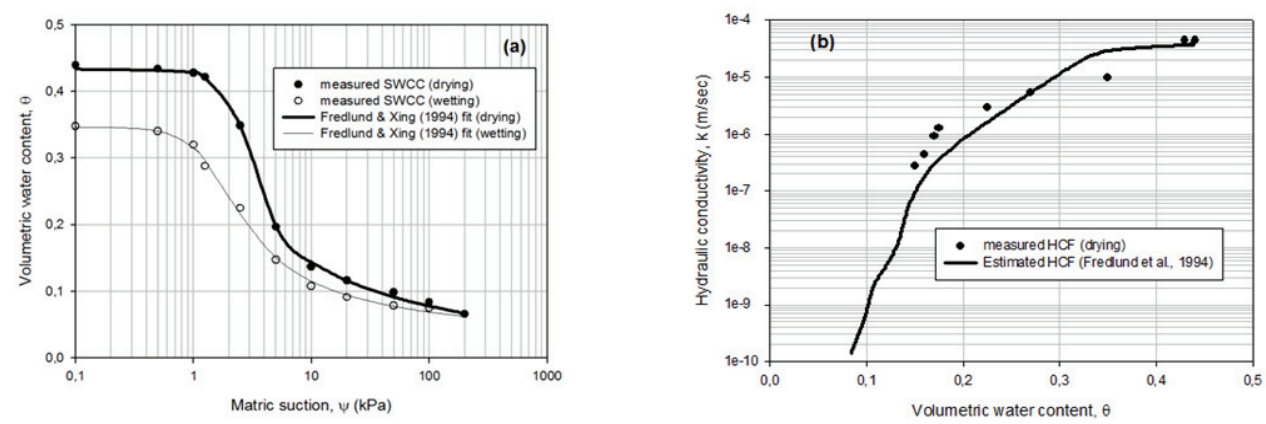

Figure 3 - (a) Soil-water characteristic curves and (b) hydraulic conductivity function (data from [4, 18]). 
Air Entry Value: Grain size distribution directly controls the pore size distribution (not only the pore size) [22-25]. Therefore, three hypothetical soils with different AEVs are generated by multiplying grain size distribution data of Edosaki sand by 0.5, 2.0 and 4.0 (Fig. 4). Because AEV of a soil is a measure of its pore size, SWCCs of four hypothetical soils are obtained by scaling the suction values of Edosaki sand SWCC by 0.5, 2.0 and 4.0, whereas volumetric water content values data remain constant. Obviously air entry value in these soils is $0.5,2.0$ and 4.0 times that of Edosaki sand $(1.75 \mathrm{kPa})$, respectively. These hypothetical soils/SWCCs are designated as "AEV=0.88", "AEV=3.5", "AEV=7.0", all values having the unit of $\mathrm{kPa}$ (Fig. 5a). Names of the soils according to Unified Soil Classification System (USCS), mean particle size $\left(\mathrm{D}_{50}\right)$, and fines content (\% smaller than $\left.0.074 \mathrm{~mm}\right)$ are given in Table 1 . In order to generate hydraulic conductivity functions of four hypothetical soils, saturated hydraulic conductivity $\left(\mathrm{k}_{\mathrm{s}}\right)$ values are needed as input in the method proposed by [21]. Saturated hydraulic conductivity is assumed to be proportional to the square of particle or pore size, based on pipe flow equations and empirical correlation between permeability and effective grain size (equation 1) by [28]

$\mathrm{k}=\mathrm{C} \cdot\left(\mathrm{D}_{10}\right)^{2}$

Where $\mathrm{k}$ is the permeability in $\mathrm{cm} / \mathrm{sec}, \mathrm{D}_{10}$, effective particle size in $\mathrm{mm}$, represents a grain diameter for which $10 \%$ of the sample will be finer than it, and coefficient $\mathrm{C}$ can be taken as 1.0. Particle, or pore sizes, are assumed to be inversely proportional to AEV, based on capillary tube analogy as well as correlations by [29, 25]. Hence the original saturated hydraulic conductivity value of Edosaki sand is multiplied by 4, 1/4, 1/16 and 1/36 for respective AEV values. These values are then used as an input in the method proposed by [21] which was used to predict hydraulic conductivity functions. Figure 5 shows SWCCs of generated hypothetical soils and their predicted HCFs.

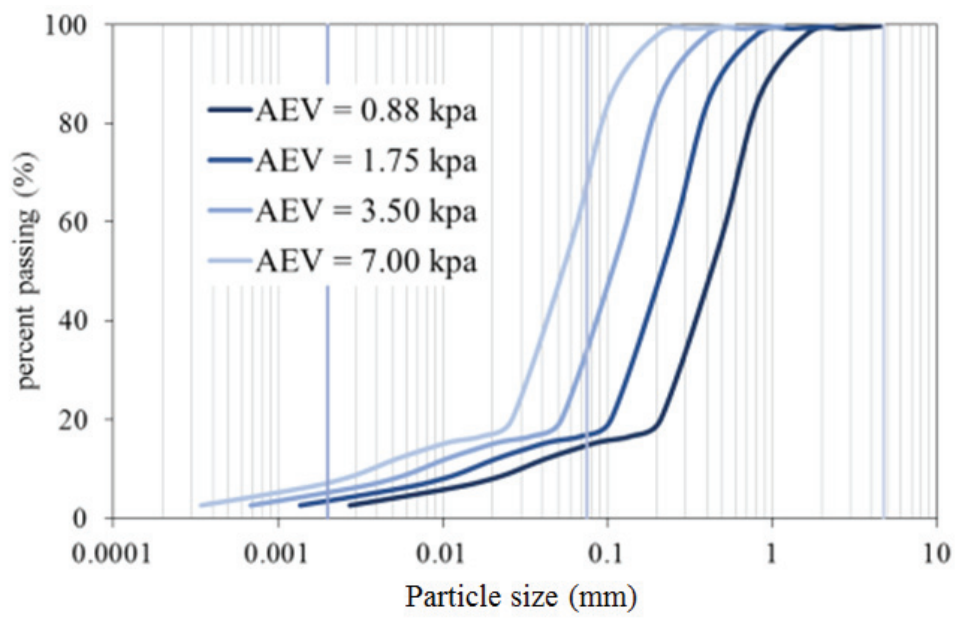

Figure 4 - Grain size distribution curves of soils with different AEVs (grain size distribution data for AEV $1.75 \mathrm{kPa}$ is taken from measured data of [4, 18]). 
Table 1 - Specification of generated hypothetical soils with different AEVs.

\begin{tabular}{|c|c|c|c|c|c|c|}
\hline Soil name & $\begin{array}{l}\mathrm{AEV} \\
(\mathrm{kPa})\end{array}$ & $\begin{array}{c}\text { USCS } \\
\text { Classification* }\end{array}$ & $\begin{array}{c}\mathrm{D}_{50} \\
(\mathrm{~mm})\end{array}$ & $\begin{array}{c}\text { Fines } \\
\text { content }(\%)\end{array}$ & $\mathrm{C}_{\mathrm{u}}$ & $\mathrm{C}_{\mathrm{c}}$ \\
\hline $\mathrm{AEV}=0.88$ & 0.88 & SM & 0.44 & 15 & \multirow{4}{*}{17.7} & \multirow{4}{*}{3.9} \\
\hline $\mathrm{AEV}=1.75$ & 1.75 & SM & 0.22 & 17 & & \\
\hline $\mathrm{AEV}=3.5$ & 3.5 & SM & 0.11 & 32 & & \\
\hline $\mathrm{AEV}=7.0$ & 7.0 & ML & 0.06 & 66 & & \\
\hline
\end{tabular}

* in USCS classification, plasticity index of the soils would be needed. The soils in this study are considered non-plastic.

Desaturation Rate: As the soil becomes more uniform, desaturation rate (defined in Fig. 2) increases. To obtain soils with different rates of desaturation, DSR of Edosaki sand (0.06) is multiplied by $0.5,2.0,4.0$ and 8.0. These hypothetical soils / SWCCs are designated as "DSR=0.03", "DSR=0.12", "DSR=0.24" (Fig. 5c). It is assumed that changes in DSR of a soil have no significant effect on its $\mathrm{k}_{\mathrm{s}}$.

Saturated Volumetric Water Content: Another set of four hypothetical soils with different $\theta_{\mathrm{S}}$ are generated by varying saturated volumetric water content values of Edosaki sand SWCC (which is 0.44 ) by increments/decrements of 0.04 ; thus, $\theta_{\mathrm{S}}$ values in the range of 0.36 to 0.52 are obtained (Fig. 5e). Physical interpretation of this action is increasing and decreasing dry density of hypothetical soil. A soil with a higher $\theta_{\mathrm{S}}$ value is a looser soil. Saturated hydraulic conductivity of these newly generated soils, to be used as an input in HCF estimation at SEEP/W, are deduced from permeability of Edosaki sand considering density of each hypothetical soil. Pipe flow equation and volume mass relations are used to derive a relation between $\mathrm{k}_{\mathrm{S}}$ and volumetric water content.

Residual Volumetric Water Content: Soils with increased and decreased residual water content are generated from original SWCC data set of Edosaki sand (which is 0.135 ). To do so, volumetric water contents of data at residual/tail part of SWCC (with suction higher than $10 \mathrm{kPa}$ ) are increased and decreased by 0.01 (Fig. $5 \mathrm{~g}$ ).

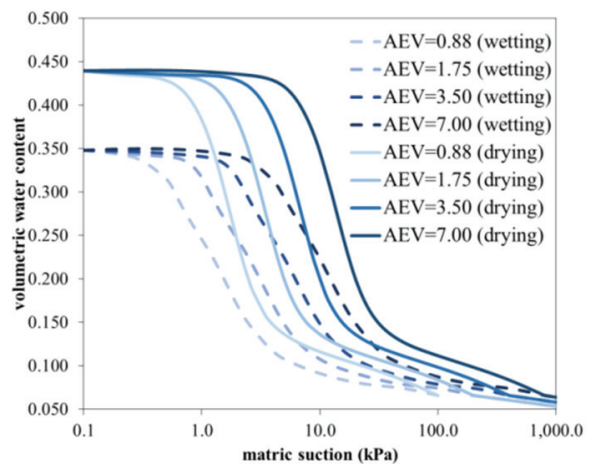

(a)

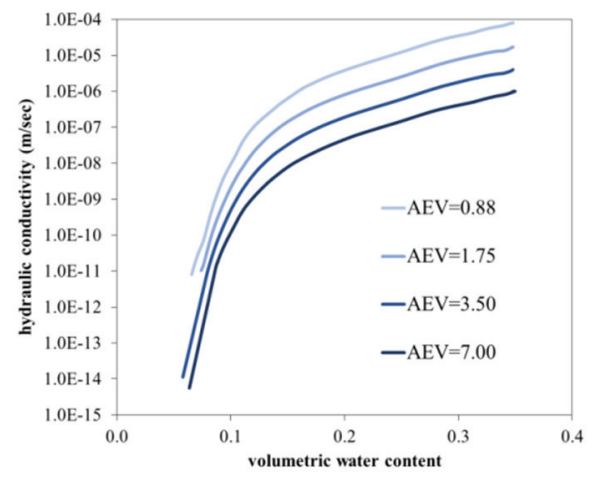

(b) 


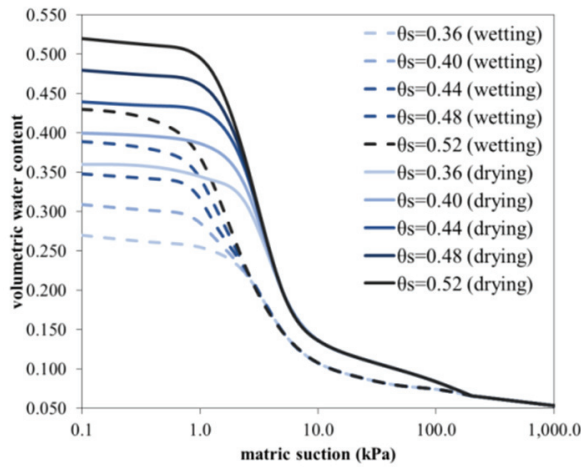

(c)

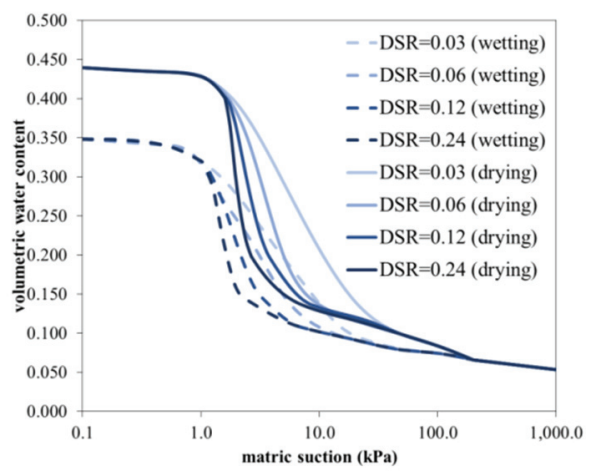

(e)

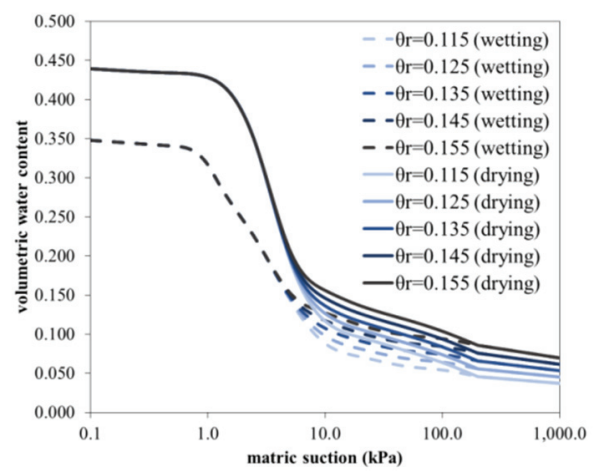

(g)



(d)

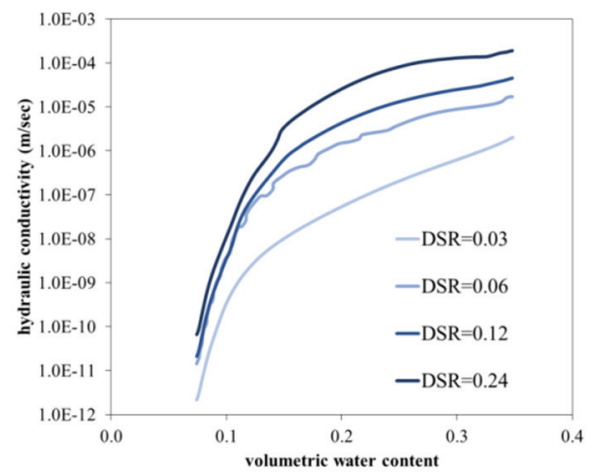

(f)

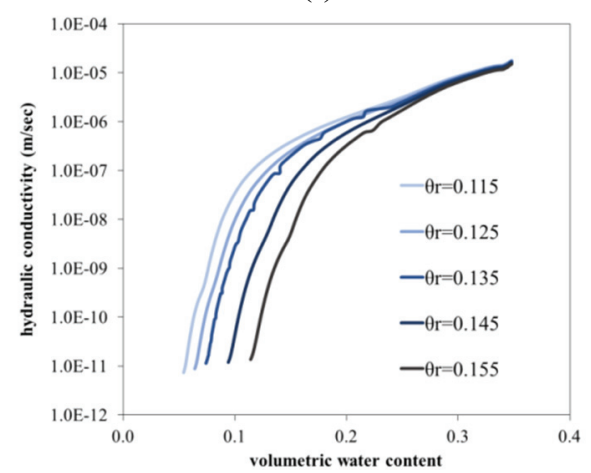

(h)

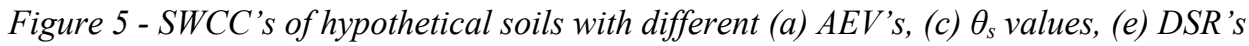
and $(g) \theta_{r}$ values. HCF's of hypothetical soils (since the hydraulic conductivity curves are plotted with volumetric water content drying-wetting hysteresis effect would not be seen) for different (b) AEV's, (d) $\theta_{s}$ values, (f) DSR's and (h) $\theta_{r}$ values. 


\section{NUMERICAL SIMULATIONS}

\subsection{Geometry and Boundary Conditions of the Finite Slope}

The numerical approach is first validated by predicting the triggering rainfall-intensity duration for a well-instrumented laboratory slope model test on Edosaki sand by $[4,18]$ in $[30,31]$. The numerical model is defined in GeoStudio 2007 software (SEEP/W and SLOPE/W) (Figure 4a). SEEP/W can model both saturated and unsaturated flows and SLOPE/W can model stability of slopes considering variable pore-water pressure conditions using limit equilibrium method [31,32]. As part of the current study, unsaturated seepage and slope stability study were performed over a hypothetical finite slope. A 10-m-high, 15m-wide model that includes a $7 \mathrm{~m}$ high, 45-degree slope is defined and then the entire spectrum of hypothetical soils were assigned to it (Figure 6a). In the finite element model, boundary conditions are considered as "no-flow" boundaries at the bottom and on the leftside of the model, since no water flow is allowed through these boundaries (Figure 6a). Other boundaries are "unit flux" boundaries since rainfall is infiltrating at a defined rate (Figure 6a).

Initial sensitivity analyses were performed to determine the required width of the model, in order to see whether a wider model geometry would give different results. Based on the sensitivity analyses, it was concluded that the results are not influenced by the boundary conditions, and that, a $15 \mathrm{~m}$ wide model was sufficient for the purposes of this study. Similarly, different heights of the model did not influence the suction values, the failure mechanisms and the failure surfaces in this study, therefore a $10 \mathrm{~m}$ high model was found to be sufficient.

A seepage analysis is carried out in two time-dependent (transient) stages at SEEP/W. These stages are;

- Equilibration stage which is a 30-day period of waiting, during which suction equilibration took place. Time period for this stage is selected so long to eliminate the effect of different drying hydraulic conductivities on equalibration of suctions.

- Rainfalling stage during which rainfall is applied and slope stability analyses are carried out.

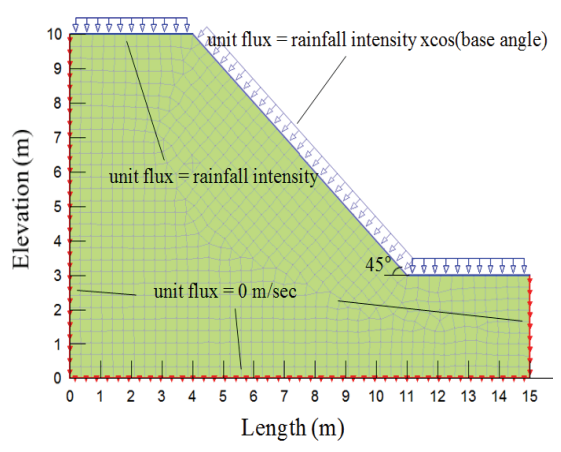

(a)

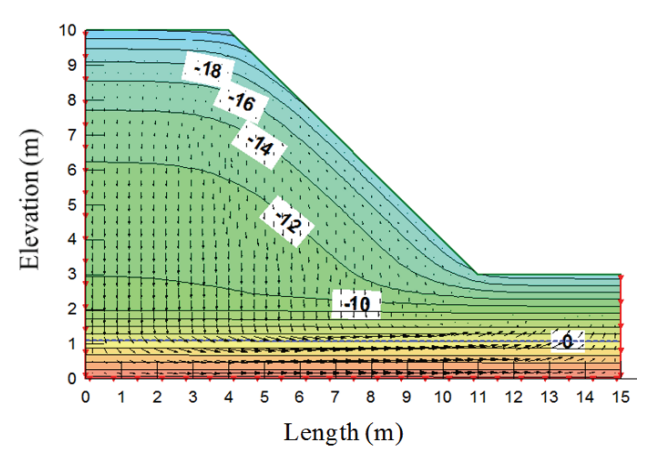

(b)

Figure 6 - (a) Geometry and boundary conditions of the finite slope model, (b) initial suction values in the slope before the rainfall application. 
The initial suction value (before equalization stage) is needed in the analyses. A constant initial volumetric water content, instead of constant initial suctions, are assumed in four hypothetical soils in Figure 4a. This is a realistic assumption, because the finer-grained soils would have higher initial suction values. For example, let's compare the suction values corresponding to volumetric water content of 0.148 for $\mathrm{AEV}=7.0 \mathrm{kPa}$ soil and for $\mathrm{AEV}=0.88$ $\mathrm{kPa}$ soil in Figure 4a, in their wetting curves. AEV=7.0 kPa soil is a finer-grained soil and has higher initial suction value. The initial volumetric water content should be a low value, but not as low as to be in the range of residual water content zone of each hypothetical soil. The reason for choosing this number as a low value is that, with the initial suction values, for the given slope angle and slope geometry, slopes should be initially stable in each of the four hypothetical soils [31]. Therefore, SWCC's of four hypothetical soils given in Figure 4a are considered when choosing the initial volumetric water content value of 0.148 for all soils (and this value corresponds to different initial suction values for each of the four hypothetical soils in Figure 4a).

After equalization stage, the values of suction that satisfy hydraulic equilibrium throughout the slope are obtained (Fig. 6b) and are taken as the initial suction values for rainfall stage. The pore water pressure distributions obtained for each time increment of seepage analysis are used in stability analyses to determine the factor of safety of the slope using SLOPE/W. For stability analyses, the pore water pressure obtained from numerical seepage analyses are used to determine the factor of safety of the slope by Morgenstern and Price (1965)'s limit equilibrium method [33]. In order to interpret shear strength of soils in unsaturated state, the method proposed by [34] is used as in equation (2)

$$
\tau=c^{\prime}+\left(\sigma_{n}-u_{a}\right) \tan \phi+\left(u_{a}-u_{w}\right) \tan \phi\left(\frac{\theta-\theta_{r}}{\theta_{s}-\theta_{r}}\right)
$$

where $\tau$ denotes shear strength of unsaturated soil, $\mathrm{c}^{\prime}$ is effective cohesion of saturated soil; $\phi^{\prime}$ is internal friction angle, $\sigma_{\mathrm{n}}$ is total normal stress on the plane of failure, $\theta$ is the volumetric water content, $\theta_{r}$ is the residual volumetric water content, $\theta_{s}$ is the saturated volumetric water content, $\mathrm{u}_{\mathrm{a}}$ and $\mathrm{u}_{\mathrm{w}}$ are pore air and water pressures, respectively. This equation is available in SLOPE/W software.

\subsection{Seepage and Stability Analyses}

By using unsaturated hydraulic properties (SWCC \& HCF) of hypothetical soils seepage and stability analyses of the model are performed under constant rainfall intensity values between 5 and $80 \mathrm{~mm} / \mathrm{hr}$ rainfall. Examples of pore water pressures and slip surfaces calculated at the time of failure (F.S.=1.00) are demonstrated in Fig. 7 through Fig. 10. It should be noted that, in this study, the effects of the surface vegetation/roots on infiltration and slope stability (and hence on I-D threshold) is not considered, however, it is anticipated that these would influence the results.

Before starting to study the effects of changes in SWCC of the soils, in order to decide on initial pore water pressure in any of numerical models, preliminary analyses were carried out on a single model with different initial water contents. The results showed that initial suction 
in the soil body can significantly affect the behavior of the slope. In all of the cases with different initial suctions, failure modes are observed to be very similar (at the time of failure). On the other hand, assuming constant initial suctions for all models (models with different SWCCs) leads to different initial water contents. Slopes with higher initial suctions require more water volume to reach failure and lower initial suctions make slopes eligible for earlier failure. Therefore, in different models, we decided to assume constant water content instead of constant suctions at the initial state. Consequently, in all analyses initial suction is set to correspond to 0.148 volumetric water content. In this way, in the models with finer soil type (e.g. higher AEVs), initial suctions (onset of analyses) are set to higher values, but they require the same volume of infiltration to reach saturation.

Air Entry Value - After analysis of the set of models with different AEVs, we observed that pore water pressure values within the soil vary from -26 to $+26 \mathrm{kPa}$ for different soil types (Fig. 7). Suction remains high in the depths of slopes with finer soil types while it is reduced only at the surface, even after a period of rainfall long enough to reach failure. This is because lower hydraulic conductivity at high suctions prevents infiltration more than a few meters beyond the surface. Therefore, only shallow failures occur in slopes composed of finer material.

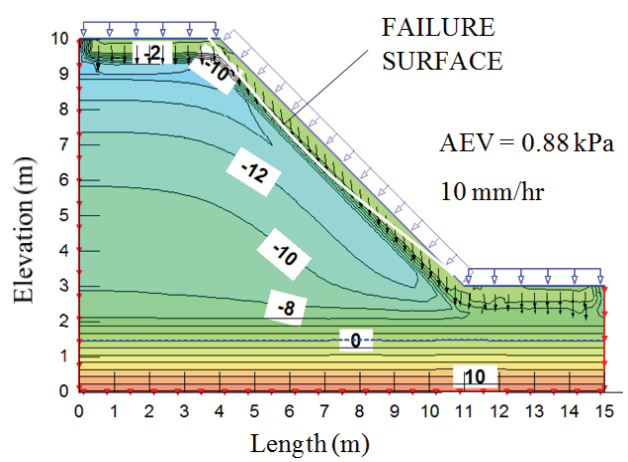

(a)

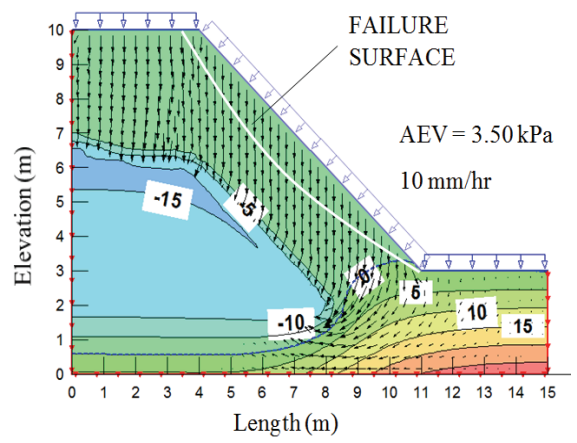

(c)

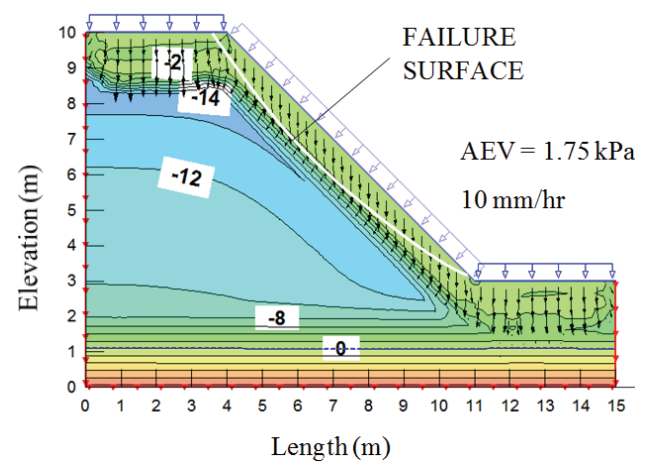

(b)

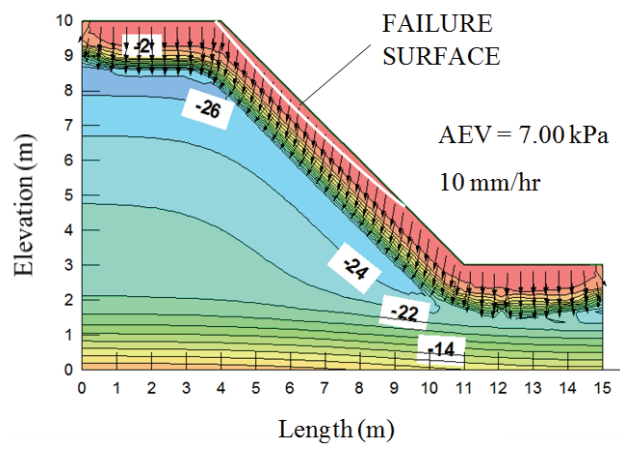

(d)

Figure 7 - Pore water pressure distribution and failure mode of slopes of hypothetical soils with different AEVs: (a) $0.88 \mathrm{kPa}$, (b) $1.75 \mathrm{kPa}$, (c) $3.50 \mathrm{kPa}$, (d) $7.00 \mathrm{kPa}$. 
Saturated Volumetric Water Content - Soils with higher $\theta_{\text {s }}$ values represent looser soils. However, this does not significantly change suction distribution and failure surface at the time of failure for the slopes composed of these soils. Numerical analyses show that for denser soils (lower $\theta_{\mathrm{s}}$ ) water table at the time of failure is deeper (Fig. 8) and slip surface is slightly shallower. However, this analysis does not consider the increase in friction angle of the soil, $\phi$, due to greater density.

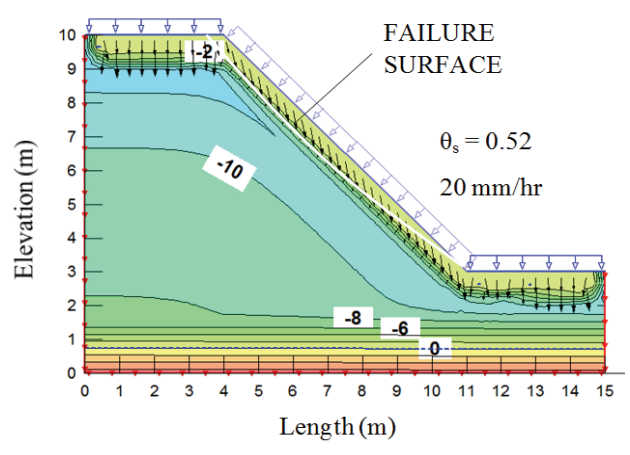

(a)

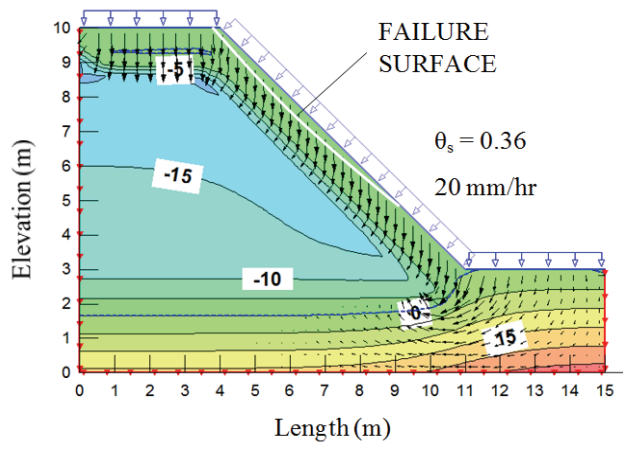

(b)

Figure 8 - Pore water pressure and failure mode of slopes composed of hypothetical soils with highest and lowest $\theta_{s}$ values: (a) 0.52, (b) 0.36 .

Desaturation rate - Desaturation rate is mostly controlled by uniformity of the grain sizes of soil. Pore water pressure distribution for highest and lowest DSR values, 0.24 and 0.03 , respectively, are demonstrated in Fig. 9. In non-uniform soils (lower DSR) due to higher initial suction values and consequently lower hydraulic conductivities, less infiltration occurs.

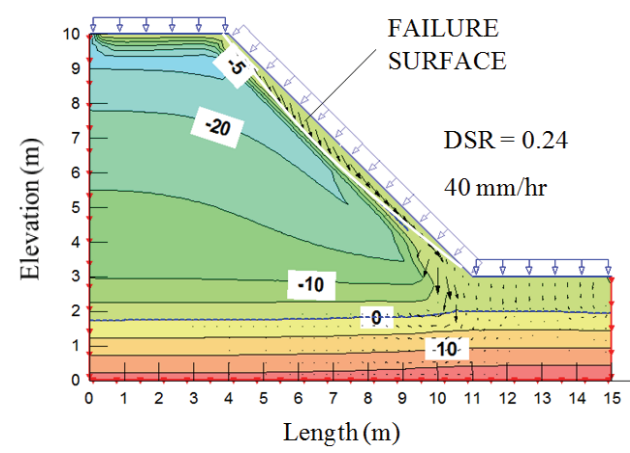

(a)

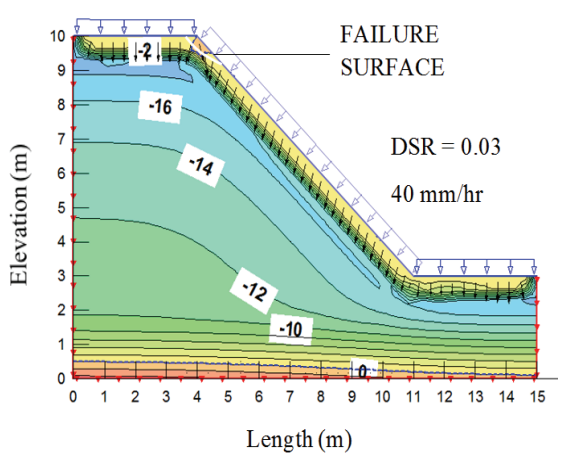

(b)

Figure 9 - Pore water pressure and failure mode of slopes composed of hypothetical soils with highest (a) and lowest (b) DSR values. 
Residual Volumetric Water Content - Changes in fines content cause significant changes in the shape of SWCC but this does not affect suction distribution in the slope of this soil. Suction distribution and the shape of slip surface in slopes with soils of different $\theta_{\mathrm{r}}$ values are very similar to those of Edosaki sand (Fig. 10). Water tables at the time of failure in these analyses are very similar despite the differences in $\theta_{\mathrm{r}}$. However differences would arise if the initial water contents were smaller.

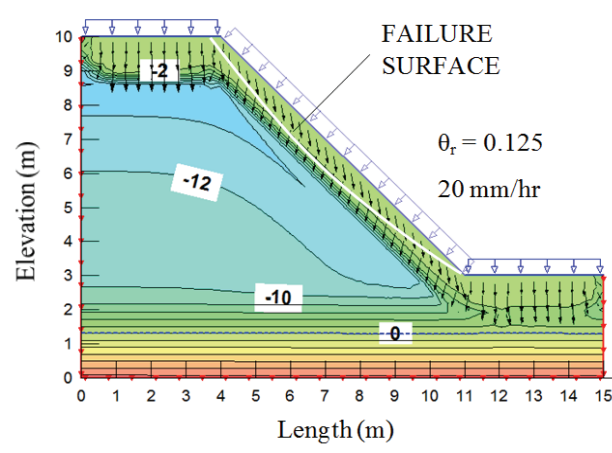

(a)

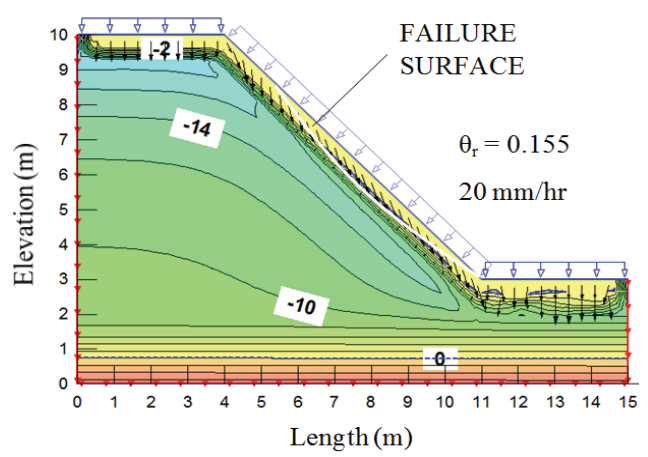

(b)

Figure 10 - Pore water pressure and failure mode of slopes composed of hypothetical soils with highest (a) and lowest (b) $\theta_{r}$ values.

It is observed that, in all of the analyses carried out in this study, the failures can be considered as "shallow landslides", i.e. the depth of failure surface is small as compared to the length of the landslide. The failure mechanisms (or causes of failure) that are observed in this study can be grouped into three categories: (A) surface erosion, (B) failure due to suction decrease, (C) positive pore water pressure development. In type (A), the surface erosion type, the failure surfaces are very shallow, i.e. less than $30 \mathrm{~cm}$ deep and suction values in the soil are high, e.g. the failure surface for AEV=7.0 in Fig. 7. Type (A) failure mechanism is shown by red colored data points in Fig. 11 and 12, which are mostly occurring at high intensity rainfall events. In cause of failure Type (B), infiltrating water progresses downward in a profile similar to a wetting front parallel to the slope surface, suctions in this zone decrease in response and lead to failure (e.g. the failure surface for $\mathrm{AEV}=0.88$ and 1.75 in Fig. 7). Type (B) failure events are represented by blue data points on the I-D thresholds in Figures 11 and 12 , generally reaching failure with lower cumulative amounts of rainfall. Type (C) failure happens in cases where the rainfall is very slow relative to the permeability (or permeability is large relative to rainfall), the water percolates all the way down to the groundwater level without causing too much decrease in suctions in the unsaturated zone. This results in a rise in groundwater level and development of positive pore pressures at the lower part of the failure arc (e.g. the failure surface for $\mathrm{AEV}=3.5$ in Fig. 7). Type (C) failure events are represented by green data points in Figures 11 and 12 . 


\subsection{Rainfall Intensity-Duration (I-D) Thresholds}

Intensity and duration are primary rainfall properties controlling the infiltration into a slope and instability. We investigated the effects of slope angle, in the range of 41 to 49 degrees, on the I-D threshold for given soil properties (Edosaki sand) and given initial moisture state (volumetric water content of 0.148 ) (Fig. 11a). It is observed that for relatively high intensity rainfalls (greater than $50 \mathrm{~mm} / \mathrm{hr}$ ) the changes in the slope angle did not influence the I-D threshold significantly. The reasoning behind this can be, at high intensity rainfalls, the rainfall does not have time to infiltrate into the ground, rather, the most of the rainfall moves down in the form of surface runoff. For rainfalls having less than $50 \mathrm{~mm} / \mathrm{hr}$ intensity, the ID thresholds differ dramatically, e.g. at a given rainfall intensity, the steeper slopes require less duration of rainfall to develop landslides, which can be expected, due to initial higher shear stresses existing in the ground before the rainfall. At a given slope angle ( 45 degrees), the changes in the initial moisture state affected the I-D thresholds, only slightly, for the given soil, and given initial moisture conditions (Fig. 11b).

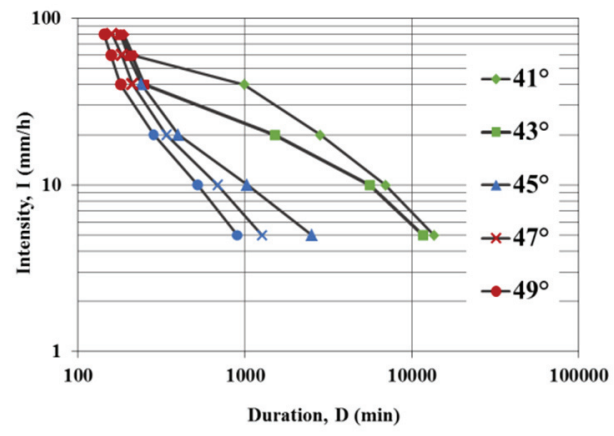

(a)

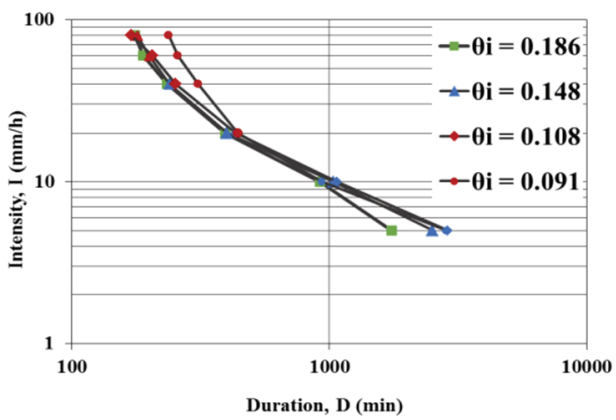

(b)

Figure 11 - Changes in I-D threshold for a given soil, (a) for a given initial moisture state, at different slope angles, (b) for a given 45 degree slope angle at different initial moisture states

I-D thresholds for different hypothetical soils and the effects of SWCC characteristics for a finite slope are shown in Fig. 12. In Figure 12, each data point corresponds to a new analysis for rainfall intensities in the range of 5 to $80 \mathrm{~mm} / \mathrm{hr}$, and each data point corresponds to the time of failure. Changes in AEV (i.e. grain size) of a soil appears to have a significant effect on I-D threshold (Fig. 12a). For a given rainfall intensity, longer duration is required to fail a slope composed of finer soil in comparison to a slope composed of coarser soil. As the soil gets finer, the difference between the durations required to trigger a landslide for highintensity and low-intensity rainfalls decreases (i.e. the slope of the I-D threshold line on a log-log plot increases). In other words, a high-intensity rainfall may trigger a landslide in a coarser soil in shorter duration in comparison to a finer soil. The exception to this is if the soil is very coarse, then failure is unreachable with a rainfall that has a low intensity since the water can freely be drained through the soil by gravity, never increasing the degree of saturation. 


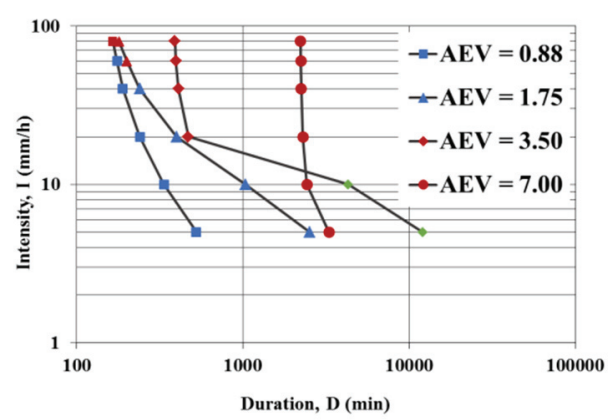

(a)

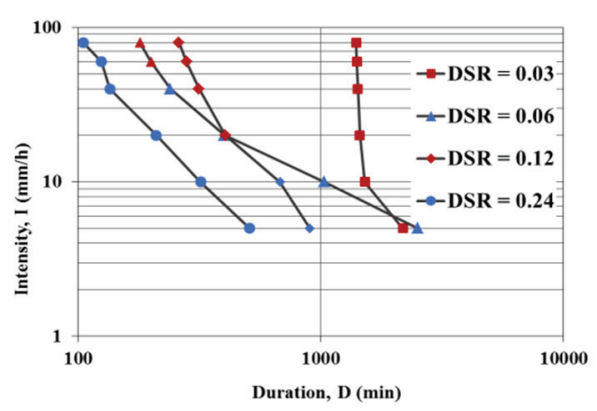

(c)

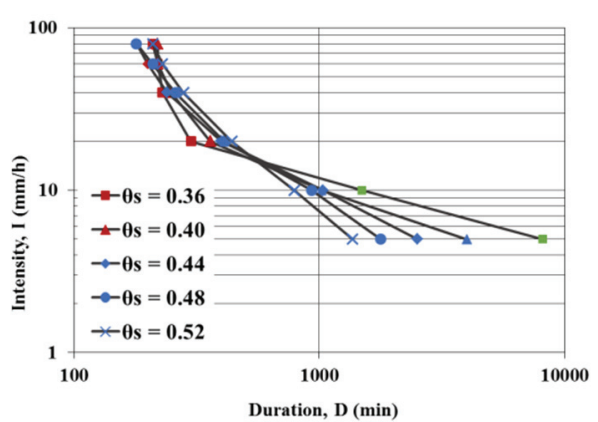

(b)

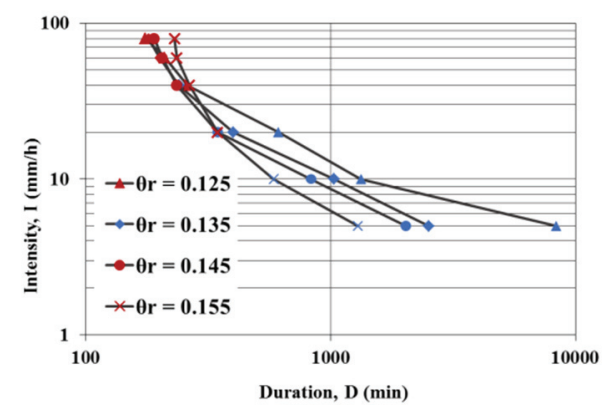

(d)

Figure 12 - I-D thresholds for soils of different AEV, $\theta_{s}$, DSR and $\theta_{r}$ values.

Saturated volumetric water content does not seem to affect the I-D threshold significantly, as compared to other parameters studied. As the saturated volumetric water content, $\theta_{\mathrm{s}}$, of the soil changes (i.e. dry density), the durations on the I-D threshold change but its inclination remains constant (Fig. 12b). For a given rainfall duration, for greater $\theta_{\mathrm{s}}$ (looser soil) higher intensity rainfalls are needed to make the slope fail. In other words, for a given rainfall intensity, longer duration rainfall is needed to cause failure as the soil gets denser. It must be noted that at lower intensities no significant difference is observed for different values of $\theta_{\mathrm{s}}$.

Increasing of desaturation rate, DSR, (i.e. uniformity) can also affect I-D plot. Slopes of soils with more uniform particle size distribution (higher DSR) tend to fail in shorter time for a given rainfall intensity (Fig. 12c). This is probably because a greater amount of water infiltrates the uniform soils faster and consequently suction is reduced sooner, reducing shear strength. In soils with non-uniform particle size distribution (low DSR) there seems to be no significant changes in stability due to DSR changes.

Value of $\theta_{\mathrm{r}}$ (i.e. fines content) also affect I-D threshold offset slightly. Soils composed of higher percent of fine particles may fail in shorter time while soils with less fine content do not tend to fail at low rainfall intensities. This has been shown in Fig. 12(d) that in low rainfall intensities (less than $20 \mathrm{~mm} / \mathrm{hr}$ ) no failure (data point) has been observed in slopes of soils with less fine content (low $\theta_{\mathrm{r}}$ value). 


\section{CONCLUDING REMARKS}

Understanding the effects of wetting/drying SWCC and HCF on I-D thresholds is a necessary first-step towards an integrated early warning system for rainfall triggered landslides that considers the physical mechanism of the problem and natural variability of soils.

The intensity-duration threshold that triggers a landslide can be computed given that the unsaturated hydraulic and shear strength properties of the soil are known.

The results indicate that different unsaturated soil properties lead to different intensityduration thresholds for the same slope geometry. Unsaturated soil properties such a SWCC and HCF play a critical role in the behavior of unsaturated slopes and in rainfall-triggering of landslides. Current study is focused on the effects of changes in controlling parameters of SWCC, namely the air entry value $(\mathrm{AEV})$, saturated water content $\left(\theta_{\mathrm{s}}\right)$, desaturation rate (DSR) and residual water content $\left(\theta_{\mathrm{r}}\right)$ on the landslide development. Among the parameters considered, air entry value (which is related to grain size) seems to be the most influential parameter on the rainfall threshold.

In coarse-grained soils, for a given rainfall intensity, as the particle size gets smaller (i.e. AEV gets larger) time to failure becomes longer due to the existence of higher suctions and slower infiltration. In other words longer duration of rainfall is needed to cause failure, and shallower slip surfaces are expected. It is observed that $\theta_{\mathrm{s}}$ (the density of the soil) does not significantly change the failure surface, suction distribution at the time of failure. For a given rainfall intensity, a looser soil (with larger $\theta_{\mathrm{s}}$ ) requires slightly longer duration rainfalls to cause the slope to fail. In soils with uniform particle size distribution (i.e. greater DSR) infiltration occurs more quickly and failure occurs in shorter time as compared to a soil with lower DSR. Changes in $\theta_{\mathrm{r}}$ (i.e. fines content) cause significant changes in the shape of SWCC but this does not affect suction distribution at the time of failure, unless the slope is initially very dry. $\theta_{\mathrm{r}}$ also offsets the I-D threshold slightly without changing its inclination.

Both "high intensity short duration" rainfalls and "low intensity long duration" rainfalls can cause landslides in unsaturated soils, as characterized by I-D thresholds. Based on the analyses carried out in this study for rainfall intensities between $5-80 \mathrm{~mm} / \mathrm{hr}$ it is observed that I-D threshold that triggers a landslide is nonlinear in a log-log plot. As the soil gets finer, the difference between the durations required to trigger a landslide for high-intensity and low-intensity rainfalls decreases (i.e. the slope of the I-D threshold line on a log-log plot increases). In other words, a high-intensity rainfall may trigger a landslide in a coarser soil in shorter duration in comparison to a finer soil. For finer grained soils, time to failure is independent of rainfall intensity above a certain level. This is because above that certain intensity, only surface runoff increases and infiltration into the soil does not change.

Three distinct failure mechanisms (or causes of failure) are observed in this study: (A) surface erosion, (B) failure due to suction decrease, (C) positive pore water pressure development. Cause of failure type (A) mostly occurs at high intensity rainfall events, cause of failure type (B) generally at lower cumulative amounts of rainfall, and type (C) in cases where the rainfall is very slow relative to the permeability and a rise in groundwater level and development of positive pore pressures at the lower part of the failure arc.

The novelties in this study, as compared to the previous physically-based models, are (i) modeling seepage and slope stability using the drying and wetting unsaturated properties of 
the soils separately for evaporation and precipitation stages respectively (i.e. considering hysteresis in SWCC; (ii) characterizing SWCC through independent physical soil properties, rather than curve fitting parameters; (iii) demonstrating the effects of unsaturated soil properties on I-D threshold.

\section{Acknowledgements}

Funding for this research was provided by the Scientific and Technological Research Council of Turkey (TUBITAK) research project No. 109M635.

\section{References}

[1] Alonso, E., Gens, A., and Delahaye, C.: Influence of rainfall on the deformation and stability of a slope in over consolidated clays: a case study, Hydrogeology Journal, 11(1), 174-192, 2003.

[2] Chen, H., Dadson, S., and Chi, Y.: Recent rainfall induced landslides and debris flow in northern Taiwan, Geomorphology, 77, 112-125, 2006.

[3] Guzzetti, F., Peruccacci, S., Rossi M., and Stark, C.P.: The rainfall intensity-duration control of shallow landslides and debris flows: an update, Landslides, 5, 3-17, 2008.

[4] Gallage, C. P. K., and Uchimura, T: Investigation on parameters used in warning systems for rain-induced embankment instability. In Kwok, Charles (Ed.) Proceedings from the 63rd Canadian Geotechnical Conference (GEO2010), GEO2010 Calgary, Calgary, Alberta, 1025-1031, 2010.

[5] Montgomery, D.R., and Dietrich, W.E.: A physically based model for the topographic control of shallow landsliding, Water Resources Research, 30(4), 1153-1171, 1994.

[6] Wilson, R.C., and Wieczorek, G.F.: Rainfall thresholds for the initiation of debris flow at La Honda, California, Environ. Eng. Geosci., 1(1), 11-27, 1995.

[7] Wu, W., and Sidle, R.C.: A distributed slope stability model for steep forested basins, Water Resour. Res., 31, 2097-2110, 1995.

[8] Iverson, R.M.: Landslide triggering by rain infiltration, Water Resources Research, 36(7), 1897-1910, 2000.

[9] Crosta, G. B., and Frattini, P.: Distributed modelling of shallow landslides triggered by intense rainfall, Nat. Hazards Earth Syst. Sci., 3, 81-93, doi:10.5194/nhess-3-81-2003, 2003.

[10] Eichenberger, J., Ferrari, A., and Laloui, L.: Early warning thresholds for partially saturated slopes in volcanic ashes, Computers and Geotechnics, 49, 79-89, 2013.

[11] Caine, N.: The rainfall intensity-duration control of shallow landslides and debris flows, Geogr. Ann., 62 A(1-2), 23-27, 1980. 
[12] Reichenbach, P., Cardinali, M., De Vita, P., and Guzzetti, F.: Regional hydrological thresholds for landslides and floods in the Tiber River Basin (central Italy), Environmental Geology, 35(2\&3), 146-159, 1998.

[13] Corominas, J.: Landslides and climate, in: Proceedings of the 8th International Symposium on Landslides, edited by: Bromhead, E., Dixon, N., and Ibsen, M. L., A. A. Balkema, Cardiff, 4, 1-33, 2000.

[14] Aleotti, P.: A warning system for rainfall-induced shallow failures, Eng. Geol., 73, 247$265,2004$.

[15] Guzzetti, F., Peruccacci, S., Rossi M., and Stark, C.P.: Rainfall thresholds for the initiation of landslides in central and southern Europe, Report, Istituto di Ricerca per la Protezione Idrogeologica, Perugia, Italy, 48 pp., 2007.

[16] Lu, N., and Godt, J.W.: Hillslope Hydrology and Stability, Cambridge University Press, Cambridge, UK, 2013.

[17] Cornforth, D.H., Landslides in Practice: Investigation, Analysis, and Remedial/Preventative Options in Soils, Wiley, 624 pages, 2005.

[18] Gallage, C., Kodikara, J., Uchimura, T.: Laboratory measurement of hydraulic conductivity functions of two unsaturated sandy soils during drying and wetting processes, Soils and Foundations, V.53(3), p. 417-430, 2013.

[19] Fredlund, D.G., Rahardjo, H., Fredlund, M.D.: Unsaturated Soil Mechanics in Engineering Practice, Wiley, 926 pages, 2012.

[20] GEO-SLOPE, SEEP/W, GEO-SLOPE International Ltd., Calgary, Alberta, Canada, 2007.

[21] Fredlund, D.G., Xing, A., and Huang, S.Y.: Predicting the permeability function for unsaturated soils using the soil water characteristic curve, Canadian Geotechnical Journal, Vol. 31, No. 4, 533-546, 1994.

[22] Arya, L.M. and Paris, J. F.: Physicoempirical model to predict the SMC from particle size distribution and bulk density data, Soil Science Society of America Journal, Vol.45, 1023-1030, 1981.

[23] Fredlund, D.G., Wilson, G.W. and Fredlund, D.G.: Use of grain size distribution for estimation of the soil-water characteristic curve. Canadian Geotechnical Journal, 39, 1103-1117, 2002.

[24] Shoarian Sattari, A. and Toker, N.K.: Obtaining soil-water characteristic curves by numerical modeling of drainage in particulate media. Computers and Geotechnics Journal, Vol. 74, 196-210, 2016.

[25] Toker, N.K.: Improvements and reliability of MIT tensiometers and studies on soil moisture characteristic curves, M.S. Thesis, Massaschusets Institute of Technology Civil Engineering Department, Boston, USA, 143 p., 2002.

[26] Fredlund, D.G. and Rahardjo, H.: Soil mechanics for unsaturated soils, John Wiley and Sons Inc. New York, 1993. 
[27] Lu, N. and Likos, W.J.: Unsaturated Soil Mechanics, John Wiley \& Sons, NJ, 2004.

[28] Hazen, A.: Water Supply, In American Civil Engineers Handbook. John Wiley \& Sons, New York, p.1444-1518, 1930.

[29] Sjoblom, K.J.: The mechanism involved during the desaturation process of a porous matrix, Ph.D. Thesis, Massaschusets Institute of Technology Civil Engineering Department, Boston, USA, 2000.

[30] Ahmadi-adli, M., Huvaj, N., and Toker, N. K.: Rainfall triggered landslides in unsaturated soils: a numerical sensitivity analysis, in Proceedings of 10th International Congress on Advances in Civil Engineering, Middle East Technical University, Ankara, Turkey, 17-19 October 2012, Article 1179, 2012.

[31] Ahmadi-adli, M.: Shallow landslides triggered by rainfall in unsaturated soils, Ph.D. Thesis, Middle East Technical University, Civil Engineering Department, Ankara, Turkey, 2014.

[32] Ahmadi-adli, M, Huvaj, N. and Toker, N.K.: Prediction of seepage and slope stability in a flume test and an experimental field case, Procedia Earth and Planetary Science, v.9, p.189-194, 2014.

[33] Morgenstern, N.R., and Price, V.E.: The analsis of the stability of general slip surfaces, Geotechnique, Vol. 15, pp. 79-93, 1965.

[34] Vanapalli, S.K., Fredlund, D.G., Pufahl, D.E., and Clifton, A.W.: Model for the prediction of shear strength with respect to soil suction". Canadian Geotechnical Journal, 33(3), 379-392, 1996. 
